\title{
Multi-satellite simultaneous observations of magnetopause and atmospheric losses of radiation belt electrons during an intense solar wind dynamic pressure pulse
}

Zheng Xiang et al.

Correspondence to: Zheng Xiang (xiangzheng@whu.edu.cn) and Binbin Ni (bbni@whu.edu.cn)

The copyright of individual parts of the supplement might differ from the CC-BY 3.0 licence. 


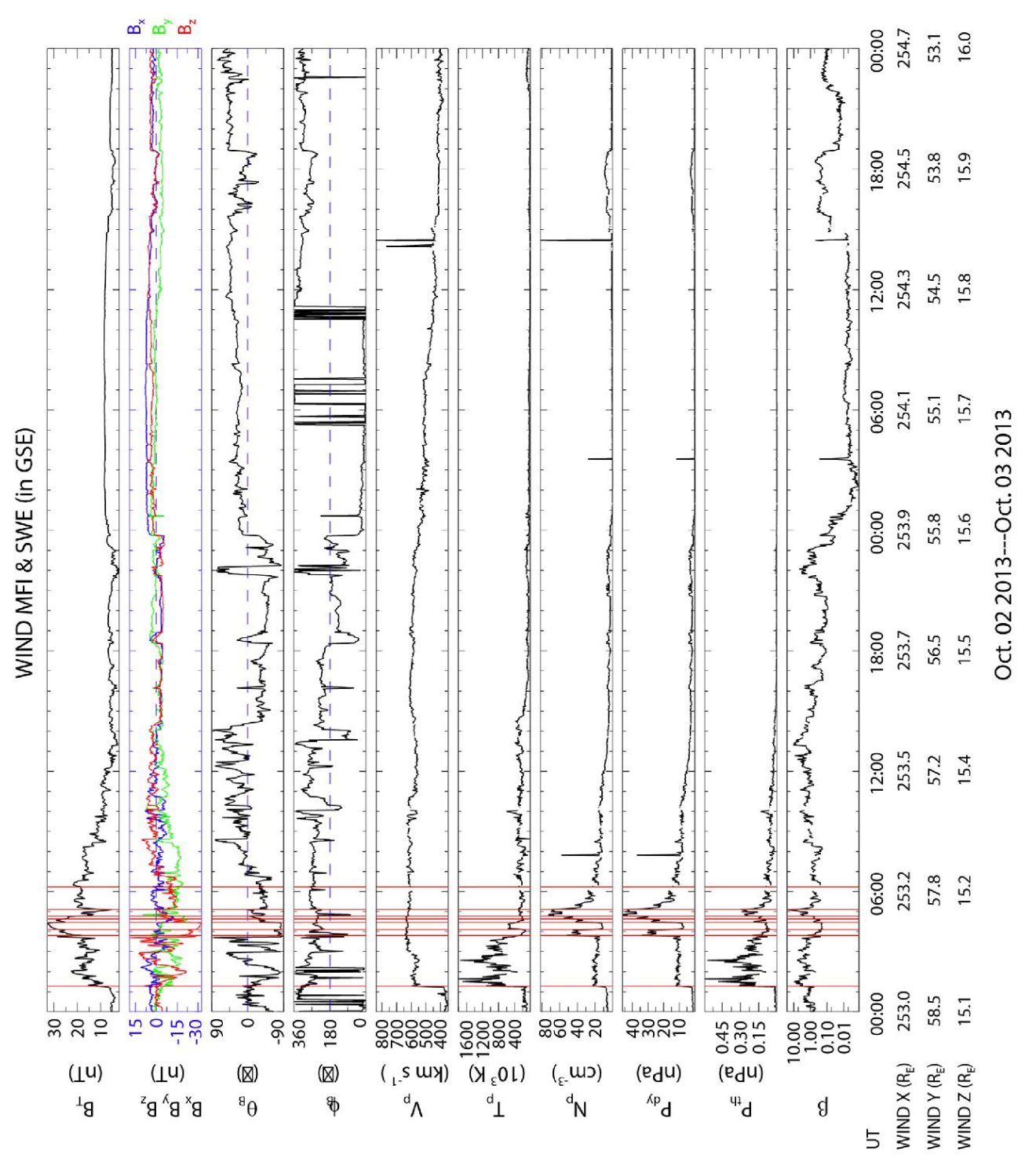

